\title{
A Tetra-Orthogonal Strategy for the Efficient Synthesis of Scaffolds Based on Cyclic Peptides
}

\author{
Nitin Jain ${ }^{1} \cdot$ Simon H. Friedman ${ }^{1}(1)$
}

Accepted: 26 October 2017 / Published online: 1 November 2017

(c) The Author(s) 2017. This article is an open access publication

\begin{abstract}
We have developed a straightforward and robust strategy for synthesizing a family of cyclic peptide scaffolds for the presentation of defined moieties in a wide range of orientations. Specifically we are exploring quinoxaline as the moiety, as a potential nucleic acid binding motif. The method requires the use of four degrees of orthogonality, which in turn allow the extension of the main chain, incorporation of the target side chains, on-resin cyclization, and the revelation of an amino group upon cleavage to increase solubility. We show that related approaches fail for a range of reasons, including the failure of cyclization. Following the optimization of the approach with a single cyclic peptide, we synthesized a family of all possible bis and tris quinoxaline adducts showing by ESI-MS that the desired full length cyclic product is produced in a majority of cases.
\end{abstract}

Keywords Cyclic peptide $\cdot$ Parallel library $\cdot$ Scaffold . Quinoxaline $\cdot$ Orthogonal $\cdot$ On-resin cyclization

\section{Introduction}

There is a need for conveniently synthesized scaffolds that can present multiple groups and allow for the variation of the groups' geometry relative to each other.(Baldini et al. 2007;

Electronic supplementary material The online version of this article (https://doi.org/10.1007/s10989-017-9642-0) contains supplementary material, which is available to authorized users.

Simon H. Friedman

friedmans@umkc.edu

1 Division of Pharmaceutical Sciences, School of Pharmacy, University of Missouri-Kansas City, 2464 Charlotte Street, Kansas City, MO 64108, USA
Mammen et al. 1998; Wu et al. 2005) Multivalent presentation is important in diverse fields such as immunology and cell recognition, and both affinity and specificity are strongly linked to the simultaneous binding of weak ligands (Badjifá et al. 2005; Kiessling et al. 2000, 2006; Lundquist and Toone 2002; Mammen et al. 1998; Strong and Kiessling 1999). This simultaneous binding in turn is linked to the spatial relationships that exist between the ligands. In this vein, we sought a convenient scaffold upon which we could vary the presentation of weakly intercalating groups, to recognize nucleic acids. Cyclic peptides are ideal for this purpose, as they can be made with high yielding reactions and have very high potential structural and conformational diversity, while having limited conformational entropy costs associated with binding (Baeriswyl and Heinis 2013; Bogdanowich-Knipp et al. 1999; Cardote and Ciulli 2016; Craik et al. 2002; Deber et al. 1976; Driggers et al. 2008; Joo 2012; Lambert et al. 2001; Schlippe et al. 2012; Tsomaia 2015; Zorzi et al. 2017).

The main challenge for the use of cyclic peptides is to establish synthetic approaches that are high yielding and that allow for the installation of the presentation groups at any position, prior to cyclization. In this work we describe the successful identification of such an approach. It utilizes four degrees of orthogonality to allow the incorporation of the presentation group (in our case quinoxaline carboxylic acid), into an amine position, followed by cyclization, and uncovering of a terminal amine, to increase solubility. We optimized the approach using a defined hexa-peptide cycle with two presented quinoxalines, and then used the approach to make a screening library of 20 cyclic heptapeptides representing all possible two and three group presenting scaffolds. Almost all showed a majority cyclic versus linear form, and were synthesized with good crude purity. 


\section{Results and Discussion}

The overall aim of our work was to create a robust scaffold that would allow for the variation in the geometry of presentation of multiple moieties, specifically quinoxaline 2 carboxylic acid. The quinoxaline moiety is a planar aromatic system that is found in the nucleic acid binding natural product triostin. We wanted to create families of molecules that presented quinoxaline in a range of geometries. Because of this, we were not wedded to a specific motif or synthetic strategy, as long as the final molecules allowed for easy structural variation and sufficient purity/yield for screening. We found that only a narrow set of conditions allowed for a successful and robust synthesis. These conditions are shown in Scheme 1. To identify the successful conditions, we examined multiple methods to synthesize a specific sequence containing six amino acids, and two sites of quinoxaline incorporation. We will briefly describe some of the approaches that were not successful, followed by the successful method.

In all methods we examined, we attempted to create the final cycle through the side chain of an aspartic acid in the first synthetic position, and the alpha terminal amine of the final amino acid in the chain, diamino propionic acid (Dap). In the first approach we attempted (Scheme 2, top), we used Dap groups with their beta amino functionality protected by the Mtt group. After the entire linear chain was synthesized, we globally deprotected these Mtt groups (using 1\% TFA), and the resulting exposed amino groups were acylated with quinoxaline 2 carboxylic acid. The ODmab group protecting the aspartyl carboxyl and the terminal Fmoc amino groups were then simultaneously removed using $2 \%$ hydrazine, followed by HATU driven cyclization between this carboxyl and amino group. Analysis of this reaction product showed no full length product, linear or cyclic. Masses consistent with incomplete ODmab deprotection, as well as aspartimide formation and capped linear form were observed (data not shown).

A second unsuccessful approach is shown in Scheme 2, bottom. In this approach, the Dap side chain amino groups were protected by Boc groups, and the aspartic acid side chain was protected by the phenyl isopropyl (Opp) group. Five amino acids were incorporated, leaving out the final Dap. The Boc groups were selectively deprotected using trimethyl silyl triflate, after which quinoxaline 2 carboxylic acid was incorporated into the exposed amino groups. The final Dap was introduced into the terminal, and the Fmoc protected alpha amine was deprotected with $20 \%$ piperidine. The Opp group on aspartic acid was then deprotected using $1 \%$ TFA, and the cyclization effected with HATU. Analysis of the cleaved and washed final product by LC-MS showed no identifiable linear or cyclic product. It is possible that this strategy failed because of incomplete orthogonality in the deprotection of Boc in the presence of the Opp group. We were inspired in part by the work of Cavelier who showed that TMSOTf can remove Boc groups without completely cleaving peptides from Wang resin.(Lejeune et al. 2003).

The final successful strategy (Scheme 1), incorporated elements from these unsuccessful methods while introducing a fourth degree of orthogonality, which ultimately allowed for high yields of full cyclized product. In this approach, the amino acids were installed using standard Fmoc chemistry coupled with HATU. All Dap amino acids (intended as the base upon which to incorporate the quinoxaline 2 carboxylic acid) used Dde side chain protection. As each mid-chain Dap was incorporated, the Dde group was removed by reaction with the method of Bradley and coworkers, namely hydroxylamine/imidazole.(Diaz-Mochon et al. 2004; Wilhelm et al. 2000). This exposed the beta amino group, which was then immediately acylated with quinoxaline 2 carboxylic acid. We considered using a global Dde deprotection at the end of synthesis but were concerned with the possibility of Dde migration.(Wilhelm et al. 2000).

The sixth and final amino acid incorporated was Dap with a standard alpha amino Fmoc protection but with a side chain protected by a Boc group. If we had used a Dde group instead for the side chain amine protection, we again would have run the risk of Dde migration. As before, we deprotected the Opp protected aspartic acid side chain with $1 \%$ TFA, the terminal alpha amino group with $20 \%$ piperidine, and performed cyclization using HATU. The final product was cleaved from resin using $90 \% \mathrm{TFA} / \mathrm{H}_{2} \mathrm{O}$. This also cleaved the Boc group from the side chain amine of the terminal Dap group. This amino group was included to introduce positive charge, needed for solubility and to potentially enhance binding to nucleic acid targets.

Using this strategy, we observed the desired cyclized full length product. Figure 1 shows both the HPLC trace and the ESI mass spectrum. The $320 \mathrm{~nm}$ chromatogram (lambda max of quinoxaline) shows a single sharp peak, and the ESI mass spectrum for the product indicates an $\mathrm{MH}+\mathrm{m} / \mathrm{z}$ of 799.6, with the expected $\mathrm{MH}+\mathrm{m} / \mathrm{z}$ being 799.3

With these successful conditions in place, we then focused on creating a library of compounds, in which the moieties being presented (in our case, quinoxaline) were systematically varied in their position in the motif. To increase diversity and to examine the robustness of the approach with a related motif, we expanded the peptide cycle to seven amino acids, a larger and potentially more challenging cycle to form. As before, the first amino acid (aspartic acid) side chain carboxyl, and the last amino acid (Dap) terminal amine were used to effect the final cyclization. Between them, we placed five positions that were either presentation positions (Dap acylated with quinoxaline) or spacer positions (Gly). With this motif we had theoretically ten possible bis products $(5 \times 4 / 2$ !) and ten possible tris products $(5 \times 4 \times 3 / 3$ !), 
Scheme 1 Successful scaffold synthesis approach
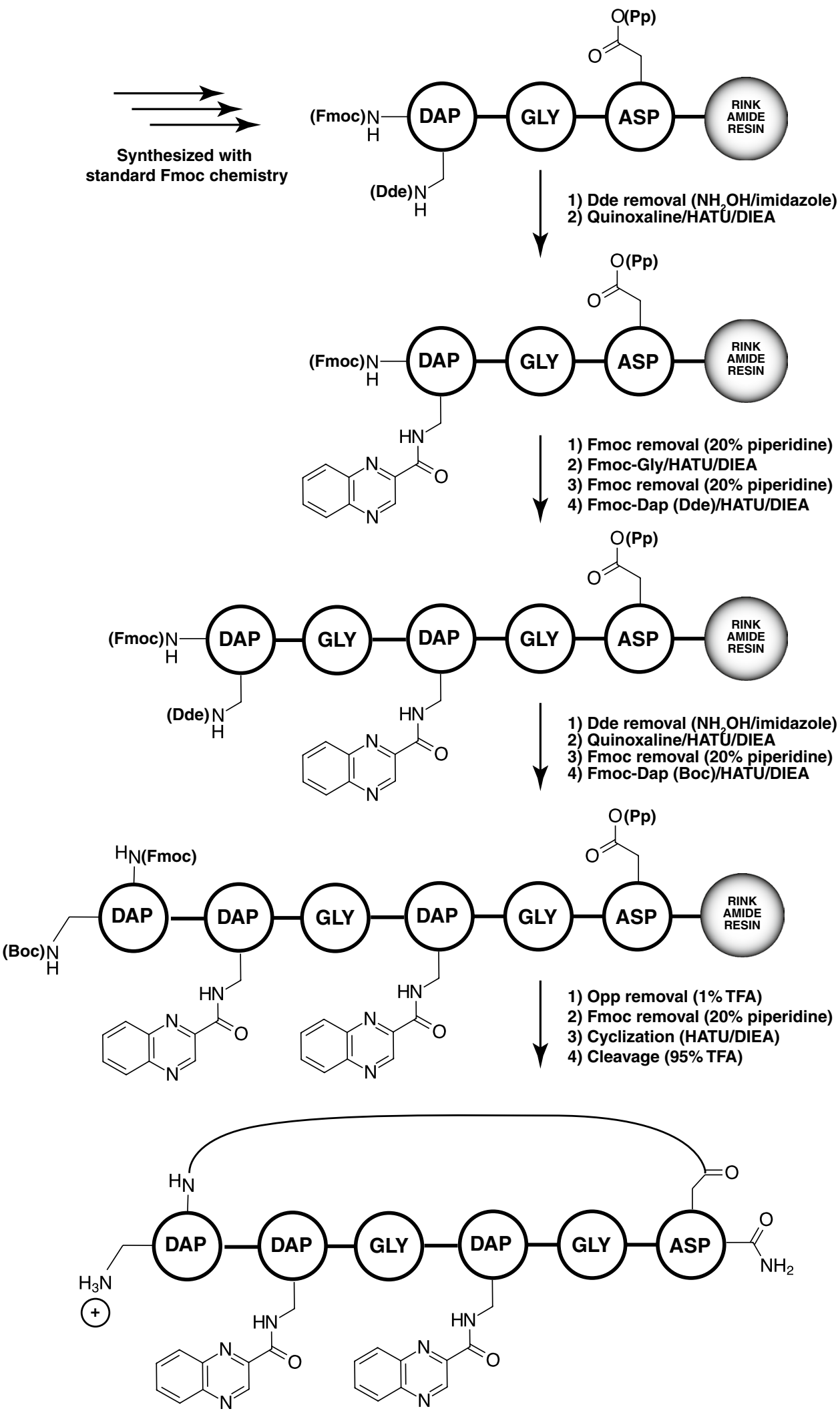

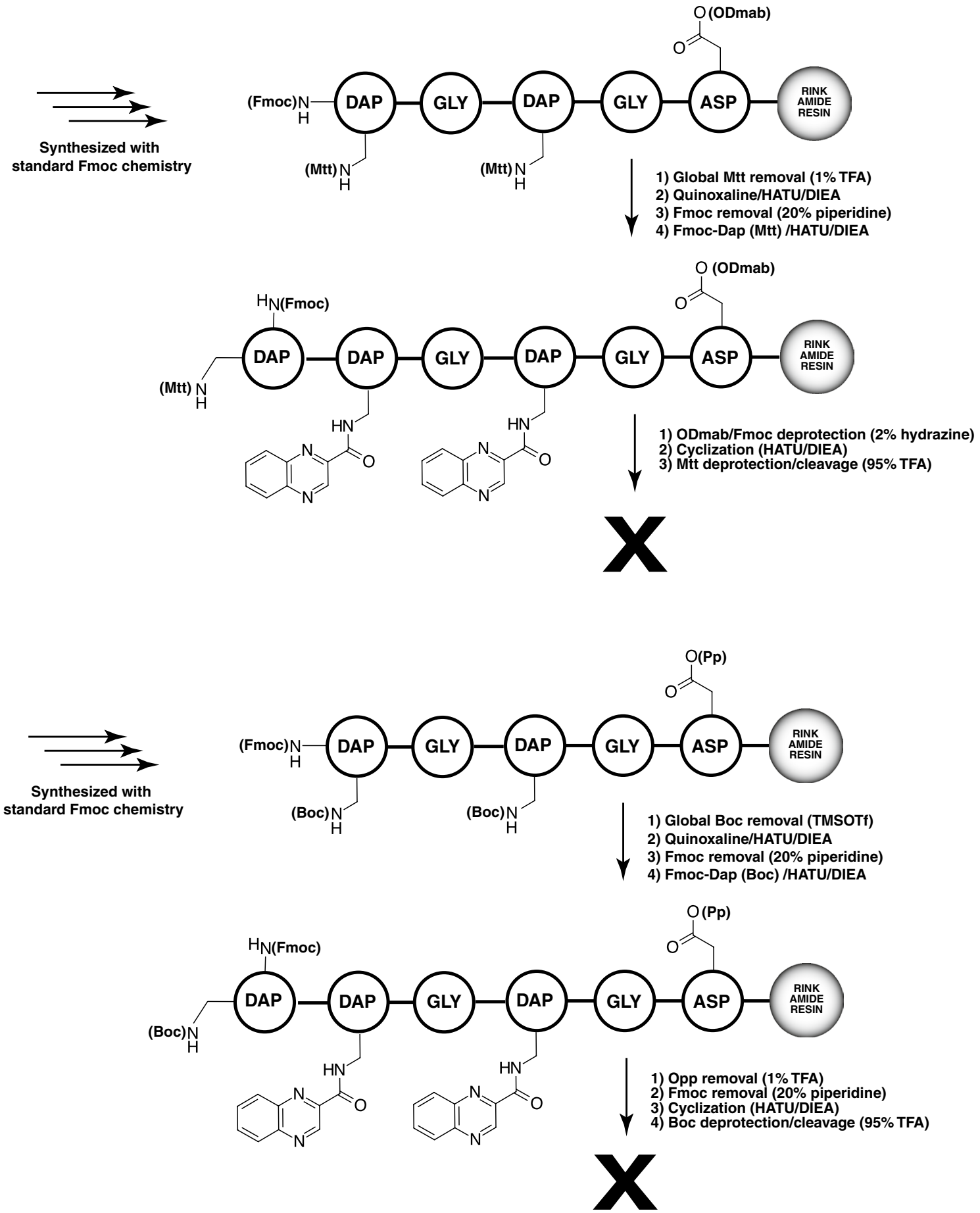

Scheme 2 Unsuccessful scaffold synthesis approaches

all of which we synthesized. In addition, we synthesized one product with a single Dap in the motif. These structures are summarized in Fig. 2.

A representative result of the synthesis is shown in Fig. 3 (compound 10). Both HPLC and MS of the crude reaction products are shown. The HPLC chromatogram shows a major sharp peak, and the ESI-MS spectrum confirms the expected mass of the cyclized product (MH+expected 856.4, observed 856.6). For these studies we analyzed the crude reaction product, to realistically indicate the side products present. The complete HPLC and ESI-MS data for the remaining 19 peptides are shown 
Fig. 1 Characterization of cyclic hexapeptide synthesized with successful scaffold synthesis approach. HPLC trace at $320 \mathrm{~nm}$ (bottom) and direct infusion ESI-MS (inset) of peptide
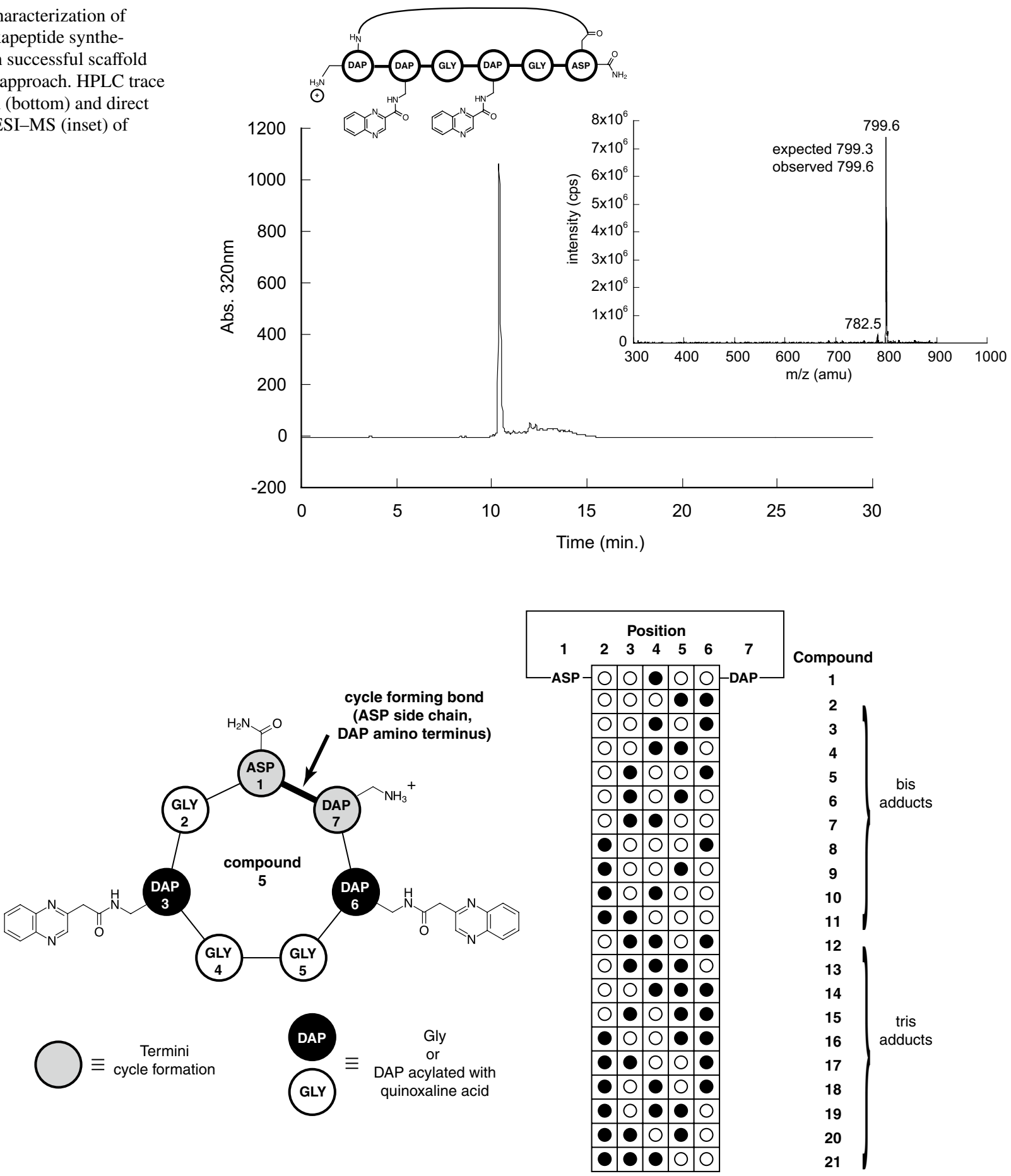

Fig. 2 Setup of heptapeptide library

in the Supporting Information, and summarized in Table 1. The synthetic approach proved to be robust, and all expected species were confirmed to be synthesized by MS. In a large majority of the cases, the major species observed in MS is the cyclized form, with small amounts showing the expected+18 mass of the linear form. In four of the tris-adducts, we observe both cyclic and linear forms present, with linear being in the majority. This is reasonable given the greater steric crowding found in tris adducts, making cyclization more challenging. In approximately half of the bis-quinoxaline species we observe a single peak in the HPLC chromatogram. In the other half of cases 
Fig. 3 Characterization of representative cyclic peptide (compound 10) from heptapeptide library. HPLC trace at $320 \mathrm{~nm}$ (bottom) and ESI-MS (inset) of peptide. A $210 \mathrm{~nm}$ HPLC trace may be found in supporting information

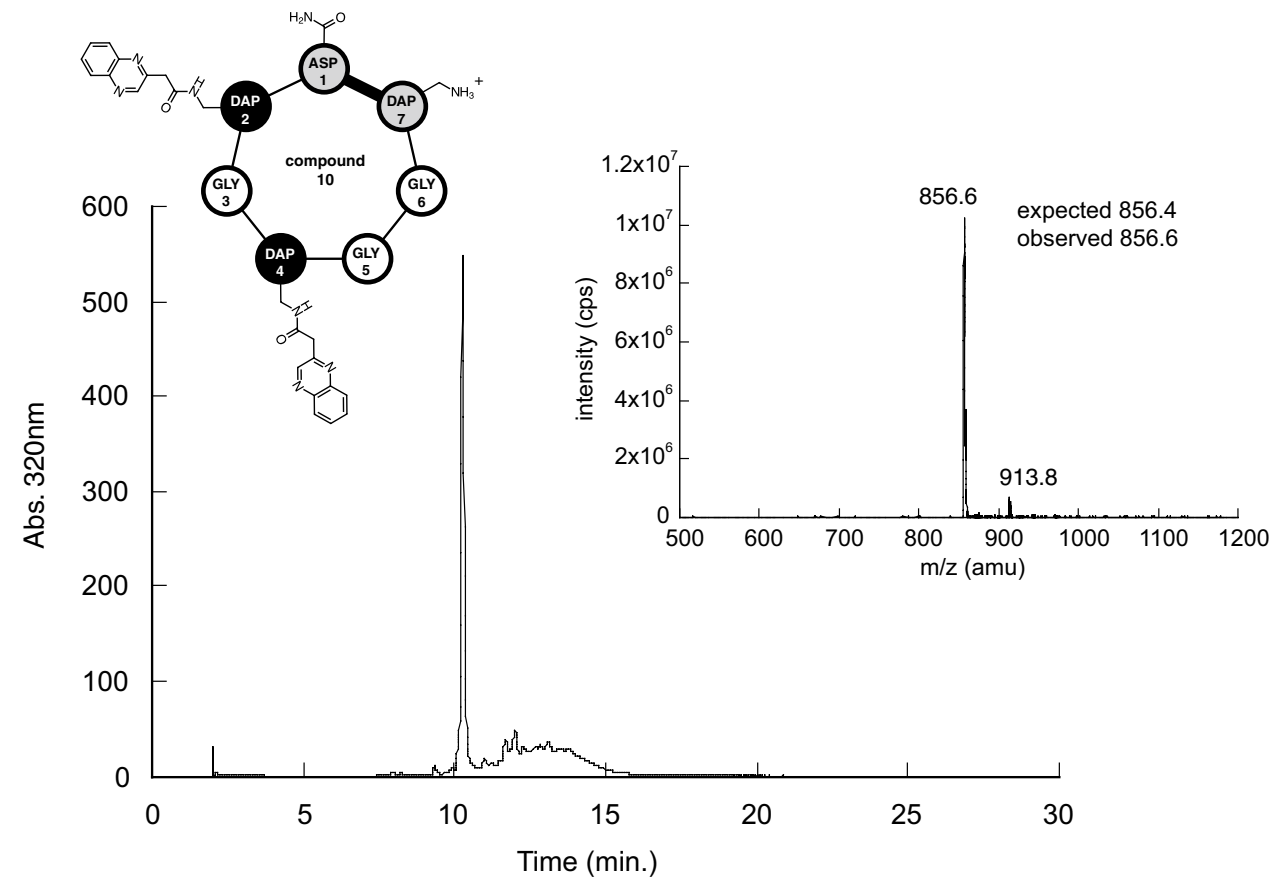

Table 1 Summary of mass spectrometric analytical data for all members of the bis and tris quinoxaline library

\begin{tabular}{|c|c|c|c|c|c|c|}
\hline Species \# & $\begin{array}{l}\text { Sequence (middle Dap positions ulti- } \\
\text { mately modified with quinoxaline acid) }\end{array}$ & \# Of mods & $\begin{array}{l}\text { Largest MS } \\
\text { signal (amu) }\end{array}$ & $\begin{array}{l}\text { Expected MS } \\
\text { signal (amu) }\end{array}$ & Yield $(\%)^{\mathrm{a}}$ & $\begin{array}{l}\% \text { HPLC } \\
\text { purity } \\
(320 \mathrm{~nm})\end{array}$ \\
\hline 1 & Asp-Gly-Gly-Dap-Gly-Gly-Dap & 1 & 671.5 & 671.4 & 41 & 84 \\
\hline 2 & Asp-Gly-Gly-Gly-Dap-Dap-Dap & 2 & 856.5 & 856.5 & 39 & 35 \\
\hline 3 & Asp-Gly-Gly-Dap-Gly-Dap-Dap & 2 & 856.6 & 856.6 & 28 & 39 \\
\hline 4 & Asp-Gly-Gly-Dap-Dap-Gly-Dap & 2 & 856.5 & 856.5 & 35 & 69 \\
\hline 5 & Asp-Gly-Dap-Gly-Gly-Dap-Dap & 2 & 856.4 & 856.7 & 33 & 53 \\
\hline 6 & Asp-Gly-Dap-Gly-Dap-Gly-Dap & 2 & 856.5 & 856.3 & 26 & 79 \\
\hline 7 & Asp-Gly-Dap-Dap-Gly-Gly-Dap & 2 & 856.4 & 856.7 & 34 & 60 \\
\hline 8 & Asp-Dap-Gly-Gly-Gly-Dap-Dap & 2 & 856.5 & 856.6 & 31 & 64 \\
\hline 9 & Asp-Dap-Gly-Gly-Dap-Gly-Dap & 2 & 856.5 & 856.4 & 28 & 56 \\
\hline 10 & Asp-Dap-Gly-Dap-Gly-Gly-Dap & 2 & 856.4 & 856.4 & 28 & 76 \\
\hline 11 & Asp-Dap-Dap-Gly-Gly-Gly-Dap & 2 & 856.4 & 856.5 & 25 & 75 \\
\hline 12 & Asp-Gly-Dap-Dap-Gly-Dap-Dap & 3 & 1041.5 & 1041.4 & 31 & 81 \\
\hline 13 & Asp-Gly-Dap-Dap-Dap-Gly-Dap & 3 & 1041.6 & 1041.5 & 36 & 79 \\
\hline 14 & Asp-Gly-Gly-Dap-Dap-Dap-Dap & 3 & 1041.5 & 1041.4 & 36 & 25 \\
\hline 15 & Asp-Gly-Dap-Gly-Dap-Dap-Dap & 3 & 1041.6 & 1041.4 & 29 & 49 \\
\hline 16 & Asp-Dap-Gly-Gly-Dap-Dap-Dap & 3 & 1041.5 & 1041.5 & 28 & 48 \\
\hline 17 & Asp-Dap-Dap-Gly-Gly-Dap-Dap & 3 & 1059.5 & 1041.5 & 38 & 30 \\
\hline 18 & Asp-Dap-Gly-Dap-Gly-Dap-Dap & 3 & 1041.5 & 1041.4 & 27 & 24 \\
\hline 19 & Asp-Dap-Gly-Dap-Dap-Gly-Dap & 3 & 1059.4 & 1041.4 & 39 & 34 \\
\hline 20 & Asp-Dap-Dap-Gly-Dap-Gly-Dap & 3 & 1059.4 & 1041.4 & 40 & 39 \\
\hline 21 & Asp-Dap-Dap-Dap-Gly-Gly-Dap & 3 & 1059.4 & 1041.4 & 41 & 48 \\
\hline
\end{tabular}

${ }^{a}$ Yield and purity determined as described in supporting information 
with bis-quinoxalines and a majority of tris-quinoxalines we observe a doubling of the HPLC peak. This may be due to the linear/cyclic issue just described.

\section{Conclusions}

In this work we have identified a synthetic approach that allows for the synthesis of a set of cyclic peptide scaffolds for the presentation of specific groups in a complete and exhaustive manner. While there have been many methods described for synthesizing cyclic peptides (Bock et al. 2013; George et al. 2008; Jeon et al. 2009; White and Yudin 2011, 2012), atypically our approach allows for the convenient installation and variation of presented moieties during the synthesis. Although we focused on a specific group, the quinoxaline ring, the exact identity of this group can be varied with each presentation position, and can be essentially any carboxylic acid. This greatly expands the variability available. In addition, the ability to incorporate two and even three presented groups while still permitting efficient cyclization broadens the method's utility.

The synthesis relies on four degree of orthogonality, allowing the building of the peptide main chain, installation of the target side chains, on-resin cyclization and finally revelation of an amine to increase solubility. We have made the complete and exhaustive set of 10 bis and 10 tris derivatives. The diversity of the motif can be expanded by using both $\mathrm{L}$ and $\mathrm{D}$ amino acids in the Dap and Asp positions, increasing diversity by a factor of 16 for the bis family and 32 for the tris family. Further diversity can be introduced through variation of the glycine positions to include the complete standard set of $\mathrm{L}$ and $\mathrm{D}$ amino acids. The final potential diversity of this cyclic family exceeds 20 million. We anticipate that the amino acid incorporation will not only introduce functional variation, but also significant conformational variation, as the effect of the amino acid side chains propagate through the overall structure. This relatively straightforward synthetic strategy represents a useful starting point for the creation of conformationally restricted molecules that can present desired moieties in a wide and diverse set of orientations. This, in turn, can make them useful for exploring biological systems in which such multivalent presentation is critical.

\section{Materials and Methods}

Detailed synthetic procedures, and complete HPLC and MS data for all library members can be found in supporting information.
Acknowledgements This work was supported by NIH grant RO1CA090410. The authors wish to thank Professor William Gutheil for curating the instruments used to generate MS data.

Funding This study was funded by the NIH (Grant No. RO1-CA090410).

\section{Compliance with Ethical Standards}

Conflict of interest The authors declare that they have no conflict of interest.

Ethical Approval This article does not contain any studies with human participants or animals performed by any of the authors.

Open Access This article is distributed under the terms of the Creative Commons Attribution 4.0 International License (http://creativecommons.org/licenses/by/4.0/), which permits unrestricted use, distribution, and reproduction in any medium, provided you give appropriate credit to the original author(s) and the source, provide a link to the Creative Commons license, and indicate if changes were made.

\section{References}

Badjifá JD, Nelson A, Cantrill SJ, Turnbull WB, Stoddart JF (2005) Multivalency and cooperativity in supramolecular chemistry. Acc Chem Res 38:723-732. https://doi.org/10.1021/ar040223k

Baeriswyl V, Heinis C (2013) Polycyclic peptide therapeutics. ChemMedChem 8:377-384. https://doi.org/10.1002/ cmdc. 201200513

Baldini L, Casnati A, Sansone F, Ungaro R (2007) Calixarene-based multivalent ligands. Chem Soc Rev 36:254-266. https://doi. org/10.1039/b603082n

Bock JE, Gavenonis J, Kritzer JA (2013) Getting in shape: controlling peptide bioactivity and bioavailability using conformational constraints. ACS Chem Biol 8:488-499. https://doi. org/10.1021/cb300515u

Bogdanowich-Knipp SJ, Chakrabarti S, Williams TD, Dillman RK, Siahaan TJ (1999) Solution stability of linear vs. cyclic RGD peptides. J Pept Res 53:530-541. https://doi. org/10.1034/j.1399-3011.1999.00052.x

Cardote TAF, Ciulli A (2016) Cyclic and macrocyclic peptides as chemical tools to recognise protein surfaces and probe protein-protein Interact. ChemMedChem 11:787-794. https://doi. org/10.1002/cmdc.201500450

Craik DJ, Simonsen S, Daly NL (2002) The cyclotides: novel macrocyclic peptides as scaffolds in drug design current opinion in drug. Discov Develop 5:251-260

Deber CM, Madison V, Blout ER (1976) Why cyclic peptides? Complementary approaches to conformations. Acc Chem Res 9:106-113

Diaz-Mochon JJ, Bialy L, Bradley M (2004) Full orthogonality between Dde and Fmoc: the direct synthesis of PNA-peptide conjugates. Org Lett 6:1127-1129. https://doi.org/10.1021/ ol049905y

Driggers EM, Hale SP, Lee J, Terrett NK (2008) The exploration of macrocycles for drug discovery-an underexploited structural class. Nat Rev Drug Discov 7:608-624. https://doi.org/10.1038/ $\operatorname{nrd} 2590$

George EA, Novick RP, Muir TW (2008) Cyclic peptide inhibitors of staphylococcal virulence prepared by Fmoc-based thiolactone 
peptide synthesis. J Am Chem Soc 130:4914-4924. https://doi. org/10.1021/ja711126e

Jeon I, Lee D, Krauss IJ, Danishefsky SJ (2009) A new model for the presentation of tumor-associated antigens and the quest for an anticancer vaccine: a solution to the synthesis challenge via ring-closing metathesis. J Am Chem Soc 131:14337-14344. https://doi.org/10.1021/ja9052625

Joo SH (2012) Cyclic peptides as therapeutic agents and biochemical tools. Biomol Therap 20:19-26. https://doi.org/10.4062/ biomolther.2012.20.1.019

Kiessling LL, Gestwicki JE, Strong LE (2000) Synthetic multivalent ligands in the exploration of cell-surface interactions. Curr Opin Chem Biol 4:696-703. https://doi.org/10.1016/ s1367-5931(00)00153-8

Kiessling LL, Gestwicki JE, Strong LE (2006) Synthetic multivalent ligands as probes of signal transduction. Angew Chem 45:23482368. https://doi.org/10.1002/anie.200502794

Lambert JN, Mitchell JP, Roberts KD (2001) The synthesis of cyclic peptides. J Chem Soc Perkin Trans 1:471-484

Lejeune V, Martinez J, Cavelier F (2003) Towards a selective Boc deprotection on acid cleavable. Wang Resin Tetrahedron Lett. 44:4757-4759. https://doi.org/10.1016/S0040-4039(03)00993-6

Lundquist JJ, Toone EJ (2002) The cluster glycoside effect. Chem Rev 102:555-578. https://doi.org/10.1021/cr000418f

Mammen M, Choi SK, Whitesides GM (1998) Polyvalent interactions in biological systems: implications for design and use of multivalent ligands and inhibitors. Angew Chem 37:2754-2794
Schlippe YVG, Hartman MCT, Josephson K, Szostak JW (2012) In vitro selection of highly modified cyclic peptides that act as tight binding inhibitors. J Am Chem Soc 134:10469-10477. https://doi.org/10.1021/ja301017y

Strong LE, Kiessling LL (1999) A general synthetic route to defined, biologically active multivalent arrays. J Am Chem Soc 121:61936196. https://doi.org/10.1021/ja990223t

Tsomaia N (2015) Peptide therapeutics: targeting the undruggable space European. J Med Chem 94:459-470. https://doi. org/10.1016/j.ejmech.2015.01.014

White CJ, Yudin AK (2011) Contemporary strategies for peptide macrocyclization. Nat Chem 3:509-524. https://doi.org/10.1038/ nchem.1062

White CJ, Yudin AK (2012) A versatile scaffold for site-specific modification of cyclic tetrapeptides. Org Lett 14:2898-2901. https:// doi.org/10.1021/ol301178r

Wilhelm RR, Srinivasan A, Schmidt MA (2000) Evaluation of ivDde as a quasi-orthogonal protecting group for Fmoc solid-phase peptide synthesis. Pept New Millenn 6:58-59

Wu P et al (2005) Multivalent, bifunctional dendrimers prepared by click chemistry. Chem Commun 5775-5777. https://doi. org/10.1039/b512021g

Zorzi A, Deyle K, Heinis C (2017) Cyclic peptide therapeutics: past, present and future. Curr Opin Chem Biol 38:24-29. https://doi. org/10.1016/j.cbpa.2017.02.006 